\title{
Editorial
}

\section{Toward Green Chemical Engineering}

\author{
Antonia Pérez de los Ríos, ${ }^{1}$ Francisco José Hernández Fernández, ${ }^{2}$ María Gómez Gómez, \\ Said Galai, ${ }^{3}$ and Pascual Pérez Ballesta ${ }^{4}$ \\ ${ }^{1}$ Chemical Engineering Department, Faculty of Chemistry, University of Murcia, 30071 Murcia, Spain \\ ${ }^{2}$ Chemical \& Environmental Engineering Department, School of Industrial Engineering, Technical University of Cartagena, \\ Murcia, 30202 Cartagena, Spain \\ ${ }^{3}$ Laboratory of Protein Engineering and Bioactive Molecules (LIP-MB), National Institute of Applied Sciences and Technology (INSAT), \\ University of Carthage, North Urban Center, BP676-1080 Tunis, Tunisia \\ ${ }^{4}$ Air and Climate Unit, Institute for Environment and Sustainability, European Commission, Joint Research Centre, \\ TP 441, 21027 Ispra, Italy
}

Correspondence should be addressed to Antonia Pérez de los Ríos; antonia.perez@upct.es

Received 29 October 2013; Accepted 29 October 2013

Copyright (C) 2013 Antonia Pérez de los Ríos et al. This is an open access article distributed under the Creative Commons Attribution License, which permits unrestricted use, distribution, and reproduction in any medium, provided the original work is properly cited.

The chemicals industry and other related industries supply us with a huge variety of essential products to everyday living. However, these industries have the potential to seriously damage our environment. In the last decade, the scientific community has witnessed a growing interest in environmental issues and the value of environmentally friendly energy generation and chemical processes. The combination of chemical engineering tools with the findings of green chemists, biologists, and environmental scientists has allowed the design of new processes for the manufacture of chemicals, fuels, and products with a much reduced environmental footprint. Furthermore, the developed environmentally benign alternative technologies have been proven to be economically superior and function as well as or better than more toxic traditional options.

In the call for papers, we invited contributions that promote the design and efficient use of environmentally benign chemical processes, including the development of processes that use clean solvents and renewable resources, biocatalysis, alternative reactors, and innovative environmental technologies for water treatment and pollution control. All contributions were peer-reviewed according to the usual high standards of this journal. Our thanks go to highly qualified and thorough referees that helped us accept seven papers. They greatly contributed to the high quality of the final papers. In the following, a brief overview and summary of the individual contributions are given.
The first contribution in this issue from G. R. L. Samanamud et al. (University of Sao Paulo, Brazil) is entitled "The application of a surface response methodology in the solar/UVinduced degradation of dairy wastewater using immobilized $\mathrm{ZnO}$ as a semiconductor." An Advanced Oxidation Process (AOPs) was carried out in this study with the use of immobilized nanometric $\mathrm{ZnO}$ and solar/UV as energy source to degrade dairy wastewater. Experiments were performed based on a surface response methodology in order to optimize the photocatalytic process. Degradation was measured in percentage terms by total organic carbon (TOC). The entry variables were $\mathrm{ZnO}$ coating thickness and $\mathrm{pH}$ using three levels of each variable. The optimized results showed a TOC degradation of $31.7 \%$. Optimal parameters were metal-plate coating of $100 \mu \mathrm{m}$ of $\mathrm{ZnO}$ and $\mathrm{pH}$ of 8.0. Since solar/UV is a constant and free energy source in most tropical countries, this process suggests an elevated potential contribution in dairy wastewater treatment, especially as a pretreatment. In addition, authors suggest that nanometric $\mathrm{ZnO}$ can be used not only for dairy wastewater treatment, but also for other types of industrial wastewater such as in the treatment of dye industry effluents, since $50 \%$ of color removal was reached in the dairy effluent.

The paper by D. Jing et al. (Chalmers University of Technology, Sweden) is entitled "Examination of perovskite structure $\mathrm{CaMnO} \mathrm{O}_{3-\delta}$ with $\mathrm{MgO}$ addition as oxygen carrier for chemical looping with oxygen uncoupling using methane and 
syngas." These authors produce cheap and environmentally friendly $\mathrm{Ca}-\mathrm{Mn}$ combined oxides with $\mathrm{MgO}$ additions with general formula $\mathrm{CaMn}_{x} \mathrm{Mg}_{1-x} \mathrm{O}_{3}$ using the spray-drying method and sintering at different temperatures. These new oxygen carriers were examined for chemical looping with oxygen uncoupling (CLOU). The active compound in the oxygen carriers was likely the perovskite material $\mathrm{CaMnO}_{3-\delta}$, and it showed highly promising results with respect to reactivity and stability. Generally, average methane conversion above $97 \%$, full syngas conversion, and substantial CLOU properties were recognized at the tested temperatures, ranging from $900^{\circ} \mathrm{C}$ to $1050^{\circ} \mathrm{C}$. It is worthy to note also the good stability showed for $\mathrm{CaMn}_{0.8} \mathrm{Mg}_{0.2} \mathrm{O}_{3}$ sintered at $1300^{\circ} \mathrm{C}$ in 50 cycles' tests. The very high reactivity with fuel gases, comparable to that of baseline oxygen carriers of $\mathrm{NiO}$, makes these perovskite particles highly interesting for commercial Chemical-Looping Combustion (CLC) application. Contrary to $\mathrm{NiO}$, oxygen carriers based on $\mathrm{CaMnO}_{3-\delta}$ have no thermodynamic limitations for methane oxidation to $\mathrm{CO}_{2}$ and $\mathrm{H}_{2} \mathrm{O}$, not to mention that the materials are environmentally friendly and can utilize much cheaper raw materials for production.

The paper "Carbonic anhydrase: an efficient enzyme with possible global implications" by C. D. Boone et al. (University of Florida, Florida, USA) highlights some of the recent accomplishments in the use of a family of enzymes known as the carbonic anhydrases (CAs) to help lower $\mathrm{CO}_{2}$ atmospheric emissions and promote biofuel production. CAs reversibly catalyze the hydration of $\mathrm{CO}_{2}$ into bicarbonate, and they are fairly inexpensive to produce and reuseable and can work at ambient temperatures. The authors proposed an optimized system that would include a cyclic production of biofuels via algal and/or microalgal cultures that would substitute for fossil fuel combustion. The flue gas could then be scrubbed for $\mathrm{CO}_{2}$ by the CAs in the same algal cultures, which would also promote the formation of bicarbonate, inducing further biomass production and increasing the rate of calcite precipitation. As such, this system would provide the benefits of reduced $\mathrm{CO}_{2}$ emissions while also providing an essentially self-enclosed fuel and calcite generator, provided that other essential ingredients and nutrients are available.

N. Lerkkasemsan and L. E. K. Achenie (Virginia Polytechnic Institute and State University, VA, USA) contribute to this issue of the journal with their paper "Life cycle costs and life cycle assessment for the harvesting, conversion, and the use of switchgrass to produce electricity." This work considers both life cycle assessment and the life cycle costs of the pyrolysis of switchgrass to use as an energy source in a conventional power plant. The process consists of cultivation, harvesting, transportation, storage, pyrolysis, transportation, and power generation. In the last step, pyrolysis oil is converted to electric power through cocombustion in conventional fossil fuel power plants. The authors found that greenhouse gas (GHG) emission from the system was negative. Therefore, based on life cycle assessment, the power generation using pyrolysis oil is environmentally friendly since it reduces GHG emissions. On the other hand, life cycle cost analysis reveals that the electricity cost per kwh is higher than the conventional technology which uses fossil fuels. However, based on the analysis, the electricity cost from pyrolysis oil could be competitive if we can utilize the system with the cheapest scenarios. They proposed a circular field entirely filled with switchgrass as the optimal scenario for reducing electricity cost because of the lower cost of cultivation, harvesting, and transport.

The next contribution in this issue from X. Zhang et al. (Sichuan University, China) is entitled "Research of hydrogen preparation with catalytic steam-carbon reaction driven by photo-thermochemistry process." The authors have studied the hydrogen preparation from steam-carbon reaction catalyzed by $\mathrm{K}_{2} \mathrm{CO}_{3}$ at $700^{\circ} \mathrm{C}$, which was driven by the solar reaction system simulated with the Xenon lamp. They found that the rate of reaction with the catalyst was 10 times more than that without catalyst, although there was no obvious change for the rate of hydrogen generation with catalyst content range from $10 \%$ to $20 \%$. It is worthy to note that the conversion efficiency of solar energy to chemical energy in this system is more than $13.1 \%$ over that by photovoltaic-electrolysis route. An analysis to the mechanism of catalytic steam-carbon reaction with $\mathrm{K}_{2} \mathrm{CO}_{3}$ is also given by the authors.

The paper by T. R. S. Baumgartner et al. (Universidade Estadual de Maringá, Brazil) is entitled "Biomass production and ester synthesis by in situ transesterification/esterification using the microalga Spirulina platensis." The production of biomass from microalgae is relatively simple, it requires light and a nutrient source, and reaches high productivity in a short time. In this work, the authors have analyzed the biomass production from the microalga Spirulina platensis and its subsequent use for in situ synthesis of alkyl esters via acid transesterification/esterification of biomass to produce biodiesel. They found the best result using ethanol as alcohol and n-hexane as a cosolvent. In situ transesterification/esterification for ester formation, aiming at producing biodiesel, adds unconventional dynamics to the use of this feedstock, in particular due to the reduction in reaction time and volume of solvents used in the process.

The last contribution in this special issue is from $\mathrm{G}$. Severa et al. (University of Hawaii, Hawaii, USA) and is entitled "Corecovery of bio-oil and fermentable sugars from oil-bearing biomass." In this work, an ionic liquid-methanol co-solvent was shown for the first time to effectively extract bio-oil and recover fermentable sugars from oil-seed biomass. This represents an improvement over current approaches that have focused solely on the recovery of bio-oil or fermentable sugars. Effective corecovery of both bio-oil and fermentable sugars was shown to require both cosolvent components with an optimal concentration of $70-30 \mathrm{wt} \%$ ionic liquid 1ethyl-3-methylimidazolium acetate to methanol ratio and a processing temperature of $120^{\circ} \mathrm{C}$. Under these conditions, nearly all the bio-oil (35.8 and $24.1 \mathrm{wt} \%$ relative to weight of whole seed) was extracted and autopartitioned to a separate immiscible phase, and approximately 25.4 and $14.3 \mathrm{wt} \%$ (relative to weight of whole seed) of fermentable sugars were recovered from the safflower and jatropha whole seeds, respectively. This constitutes a combined carbohydrate and bio-oil corecovery of 61.2 and $38.4 \mathrm{wt} \%$ of the safflower and jatropha whole seeds, demonstrating a new pathway for processing increased products from oil-seed biomass. A first 
pass model analysis suggested that the most optimal processing pathway would be to pretreat the jatropha whole seed with the co-solvent and recover bio-oil, fermentable sugars, and a protein rich meal.

The collection of works in this special issue constitutes one more step forward in the race for the development of desired, greener, more sustainable chemical processes. We are confident that much more advancements in this field will be seen in the coming years. These advancements will bring great research opportunities and excitement to researchers and practitioners working in this field and will in the same time make our living environment safer and more pleasant. We hope that you find these papers interesting and wish you much success in your research in the field of green chemical engineering.

\section{Acknowledgments}

The Guest Editors dedicate this special issue to the professors who founded the Department of Chemical Engineering at the University of Murcia: Antonio Soler Andrés, Antonio Bódalo Santoyo, Demetrio Gómez Pérez, Agustín Miñana Aznar, Manuel Rubio Torres, and José Sáez Mercader. We thank them for acting as a professional and personal reference for us. Thank you.

Antonia Pérez de los Ríos Francisco José Hernández Fernández María Gómez Gómez Said Galai Pascual Pérez Ballesta 

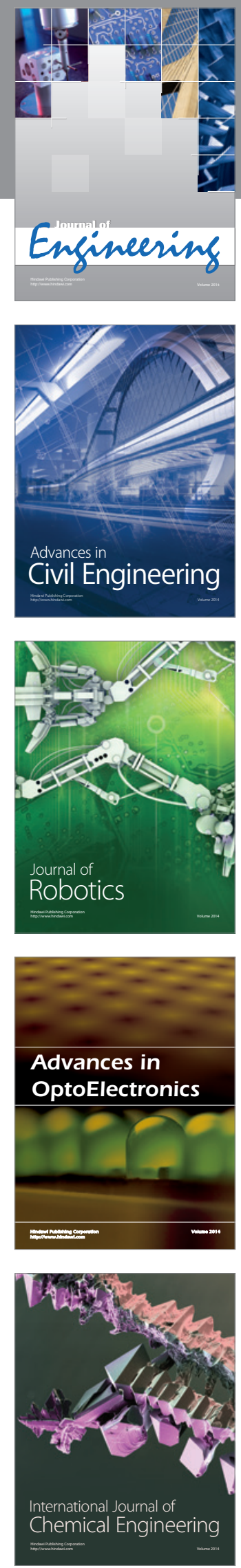

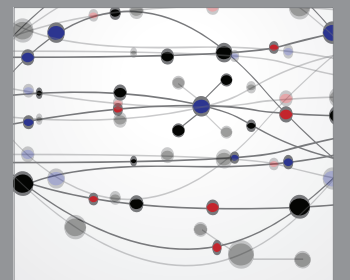

The Scientific World Journal
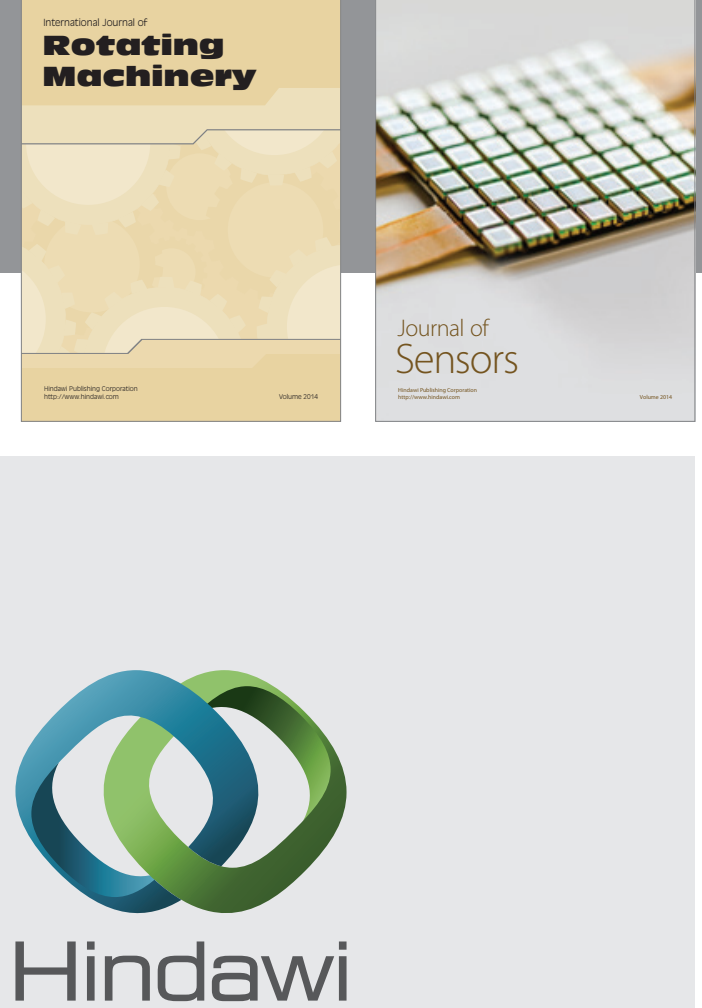

Submit your manuscripts at http://www.hindawi.com
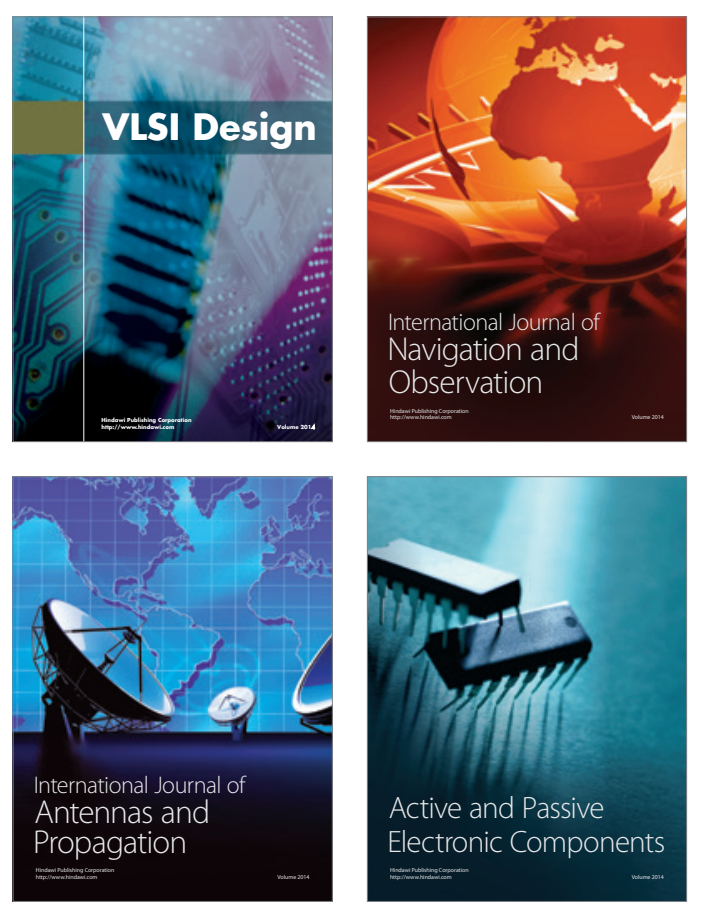
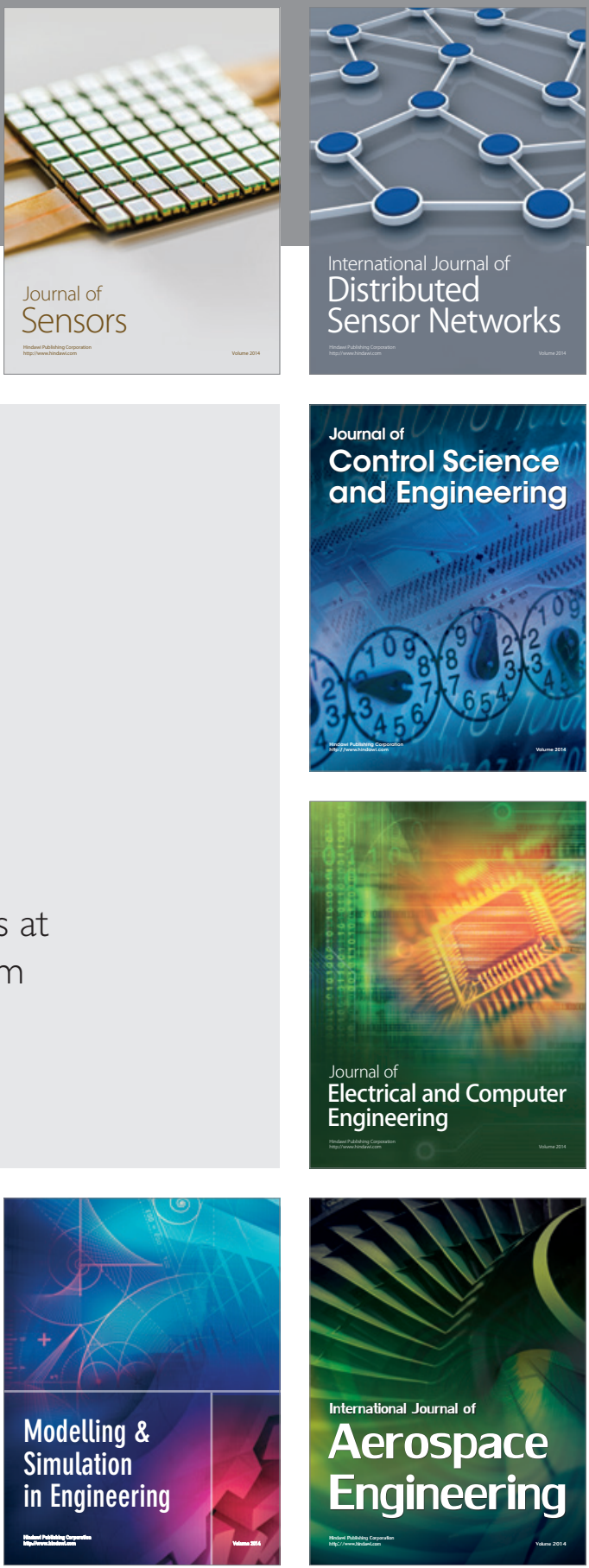

Journal of

Control Science

and Engineering
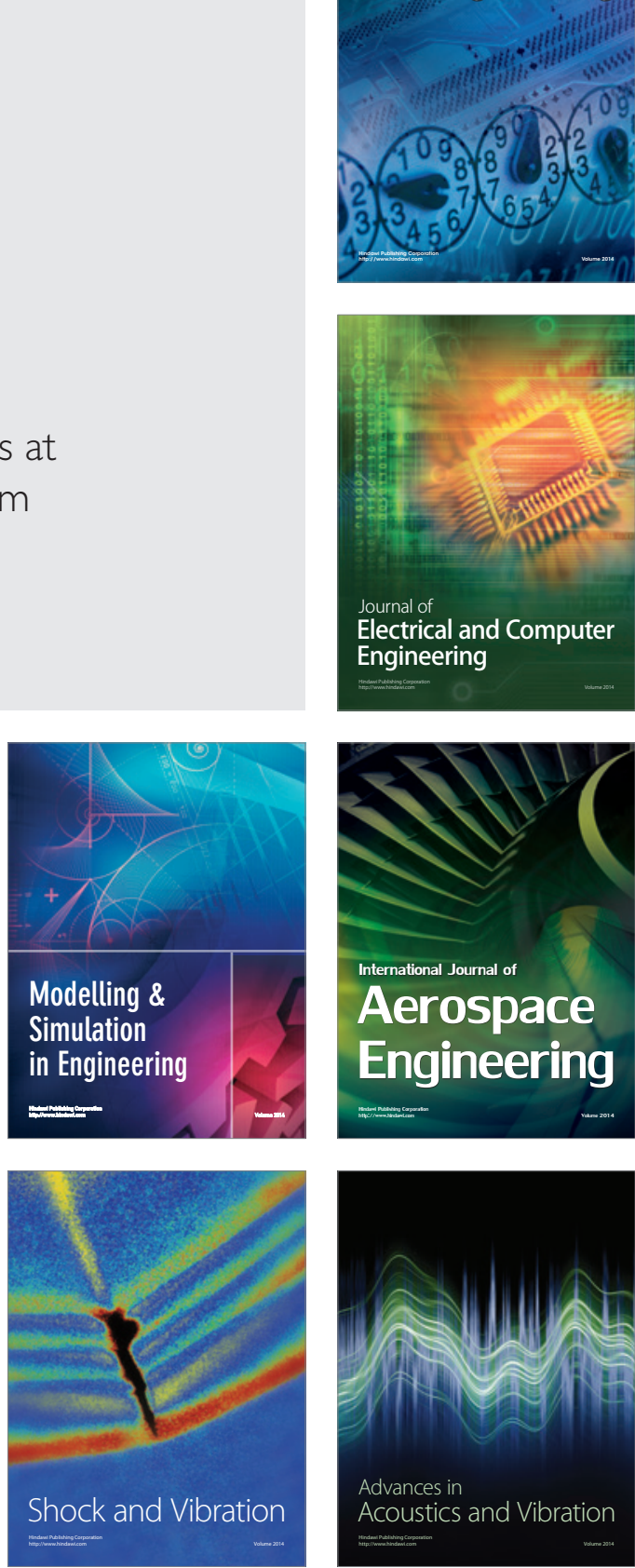